\title{
Evaluation of Different Wind Fields for Storm surge Modeling in the Persian Gulf
}

Naghmeh Afshar Kaveh ${ }^{1 *}$, Abbas Ghaheri ${ }^{2}$, Vahid Chegini ${ }^{3}$, Amir Etemad Shahidi ${ }^{4}$, Mostafa Nazarali $^{5}$

\footnotetext{
$1_{*}$ School of Civil Engineering, Iran University of Science and Technology, Narmak, Tehran, Iran, E-mail address: afshar_n@iust.ac.ir

${ }^{2}$ School of Civil Engineering, Iran University of Science and Technology, Narmak, Tehran, Iran, E-mail: ghaheri@iust.ac.ir

${ }^{3}$ National Institute for Oceanography and Atmospheric Science, Tehran, Iran, E-mail address: v_chegini@inio.ac.ir

${ }^{4}$ Griffith School of Engineering, Gold Coast campus, Griffith University, Gold Coast, QLD 4222, Australia, E-mail: a.etemadshahidi@griffith.edu.au

${ }^{5}$ Department of coastal engineering, Pouya Tarh Pars consultant engineers company, Tehran, Iran, E-mail address: mostafa.nazarali@gmail.com

* Corresponding Author
}

\begin{abstract}
With the increasing demand for accurate storm surge predictions in coastal regions, there is an urgent need to select the most accurate wind field product to use in hydrodynamic prediction models. In this study, the responses of a coastal and ocean circulation model (FVCOM) to four wind products, QuikSCAT, ECMWF ERA-Interim, GFS, and CCMP, were evaluated. Simulations of water level fluctuation with the mentioned wind forcings were compared with the tide gauge observations in the northern part of the Persian Gulf. The results show that using GFS wind field, which is a global numerical weather prediction model, produce better results compared with using other wind data sets. Although the result shows competitive improvement of the storm surge prediction between GFS and CCMP forced model, the former one excels the results almost in all stations. Root mean square error parameter of GFS forced-model for Kangan tide gauge station is 0.80 compared with those of QuikSCAT, ECMWF, and CCMP which are 0.64, 0.73, and 0.79, respectively.
\end{abstract}

Keywords: Persian Gulf; storm surge; tide; FVCOM; CCMP; QuikSCAT; ECMWF; GFS 


\section{Introduction}

Surface wind field is one of the most important surface boundary forcings for hydrodynamic models. Quality and accuracy of wind field could affect the performance of models which predicts water level fluctuations. The most accurate wind data is direct observations using buoy and meteorology stations. However, these kinds of measurement are sparse in marine environments. Hence, the use of numerical weather predictions and/or remote sensing observations is inevitable. There are several gridded global wind field, satellite observations, and blended products with different spatial and temporal resolution. For any hydrodynamic application, such as storm surge prediction, one should test their availability and accuracy in the study area and check if they could successfully resolve the orography, dominant wind direction and air pressure gradients of the region. Ruti et. al. [1] made a comparison between analyzed wind products, such as ECMWF and NCEP; and wind vectors obtained from QuikSCAT as well as direct buoy-mounted anenometers measurements. In this study, the inter comparison over the period 2000-2005 over Mediterranean sea demonstrated that the spatial resolution of the data sets represents one of the main relevant sources of errors in the analyzed wind fields. Furthermore, they confirmed that blending QuikSCAT wind data and reanalysis products could largely improve the accuracy of the wind field. They claimed that QuikSCAT data set has low accuracy in winds having less than $5 \mathrm{~m} \mathrm{~s}^{-1}$, which is a well known problem of scatterometers sensors. Agarwal et al. [2] studied on the relative performance of the QuikSCAT and NCEP/NCAR re-analysis wind through simulation by an ocean general circulation model in the tropical Indian Ocean. They showed that the sea-level anomaly simulated by QuikSCAT has less root mean square error and higher correlation with Topex/Poseidon sea level anomaly observations than the results obtained from NCEP wind field. Weller and Anderson [3] compared buoy and ECMWF analyzed wind field and showed that the latter one underestimates the wind speed in the tropical Pacific Ocean. However in another study Weller et al. [4] showed that ECMWF provides realistic winds when compared to in-situ time series measured near the coasts of Oman Sea. Another investigation conducted by Pinardi et al. [5] showed that ECMWF analysis underestimates strong winds and overestimates low winds less than $4 \mathrm{~m} \mathrm{~s}^{-1}$. This project was conducted in the framework of the Mediterranean Forecasting System Toward Environmental Prediction (MFSTEP). Comparison between QuikSCAT and buoy wind data in another region of Mediterranean Sea is reported by Pensieri et al. [6]. This study confirms that QuikSCAT wind field satisfy the accuracy requirements for high speed winds, but underestimates low winds. In addition, as 
the satellite passes over the sea only twice a day and data are sometimes taken under rainy condition, the measure wind speeds of less than $3 \mathrm{~m} \mathrm{~s}^{-1}$ are not reliable. Hence, there is an obligation to use a reference true wind over the sea for local simulations. In the most recent work, Carvalho et al. [7] compared CCMP (cross-calibrated multi-paltform), QuikSCAT and buoy wind along the Iberian Peninsula coast and proved that CCMP yields best results for wind speed and direction variability. They advised CCMP wind field for offshore wind energy and numerical applications.

One of the pioneer researches on the Persian Gulf storm surge goes back to 1989 when El Sabh and Murty [8] investigated the effect of extratropical cyclones on the water level fluctuation of the region. They believed that strong northern winds coupled with topography and tidal effects can raise water level deviations of several meters such as the storm surges observed in January of 1973 which showed negative surges between 0.5 to 1.0 meter through the Gulf. Extreme water level of the Persian Gulf is studied by Sproson [9] in the framework of PERGOS project. He estimated the total extreme water level induced by surge and wave height using some statistical methods which consider the lag between peak wave and surge events. The input wind data was 103 historical storms occurred between 1961 and 2002. The purpose of this study was to evaluate four different wind products including QuikSCAT, ECMWF, GFS, and CCMP using FVCOM numerical model. In these simulations, the water level fluctuations induced by tide and storm surge under the mentioned wind fields are compared with observed water levels through the Persian Gulf. The relative performance of each model was estimated by some statistical parameters to introduce the most accurate wind field.

\section{Methods}

\subsection{Study area}

The Persian Gulf is located in western Asia between Iran (Persia) and the Arabian Peninsula. This inland sea of some 251,000 square kilometers is connected to the Gulf of Oman in the east by the Strait of Hormuz. The length of Persian Gulf is about 990 kilometers and its width is between $56 \mathrm{~km}$ in the Strait of Hormuz and about $370 \mathrm{~km}$ in the middle parts. Maximum depth in the Gulf is 90 meter, except in the Straits of Hormuz where depths in excess of 100 meter are found [10]. The Gulf is mainly influenced by extra-tropical weather systems, 
whereas the region east of the Strait of Hormoz is affected by tropical cyclones. The dominant wind regime in the gulf is Shamal wind, a northwesterly wind, which occur mostly in winter (November to March) and summer (June to August). The onset and the strength of Shamal wind vary depending on the dynamic interaction of upper air streams and distribution of lower troposphere pressure zones. The wind speeds can reach up to $20 \mathrm{~m} \mathrm{~s}^{-1}$ and this can easily generate surface waves as high as 3.0 to 4.0 meter in the Persian Gulf and up to 1 meter positive and negative storm surge [8]. Similar to tropical cyclones, extra-tropical storms cause an offshore rise and fall of water level. However, unlike most tropical cyclone storm surge, extra-tropical storms can cause higher water levels across a large area for longer periods of time, depending on the system. Due to presence of shallow areas in the Persian Gulf, if the negative water levels is severe enough, ship berthed in harbors or those who are passing through fairway canals may beach on the coast. Examples of these shallow areas are Khur-e Musa in the north eastern part of the Gulf and Bushehr ship navigation canal in the northern section.

\subsection{Data Sources}

The required data could be divided into three categories. Bathymetry information, water level records and wind fields. Accurate bathymetric data is a necessary component to any hydrodynamic model. In order to provide Persian Gulf bathymetry information, ETOPO1 data set with 1-minute spatial resolution was used [11]. Besides some precise marine charts which are published by National Cartography Center of Iran (NCCI) were employed. In addition some local hydrographic surveys of domestic ports are gathered and put into the model. The generated bathymetry map is shown on Fig. 1.

Water level records near some of major coastal infrastructures were acquired from NCCI. This information belongs to Imam-Hasan, Kangan, and Bushehr ports (Fig. 1). Semi-diurnal tide is dominant in these regions. Temporal resolution of these mechanical tide gauge records is 30 minutes. The locations of the water level stations were selected in a way to have uniform spatial distribution along the northern coast of the Persian Gulf.

The last used data set was the wind field. According to the methodology of this study which will be described in the next section, four different data sets were used: Satellite QuikSCAT wind field, ECMWF ERA-Interim global weather model, Global Forecast System (GFS), and CCMP combined satellite wind field. 
QuikSCAT satellite is launched into space in 1999 to record world ocean 10-m sea surface wind vectors. Spatial and temporal coverage of this data set is 0.25 degree and 12 hours respectively. Gridded QuikSCAT level 3 which are prepared for academic and engineering researches are obtained from JPL NASA website. The QuikSCAT mission is finished in 2009 [12].

The ERA-Interim ECMWF wind field is published by European Center of Middle-Range Weather Forecasting [13]. This reanalysis data set is a replacement for ERA-40 wind field. The temporal coverage of this data is from 1989 till now. Spatial and temporal resolution of 10 -m wind data set is 0.75 degree and 6 hours, respectively.

Cross-Calibrated Multi Platform (CCMP) data set is developed based on different satellite observations including SSM/I, AMSRE, TRMM TMI, QuikSCAT, etc [14]. These remote sensing data sets are merged by an advanced variational data assimilation methods. In this method, a first-guess of wind field should be introduced into the model which is ECMWF operational wind field. The spatial and temporal resolutions of data are 0.25 degree and 6 hours, respectively and cover a span of 25 years (1987-2011). These data are reported at 10 meter height from the sea level.

The Global Forecast System (GFS) is a weather forecast model produced by the National Centers for Environmental Prediction (NCEP). But this data set also contains analysis fields for some variables such as wind speed components in different heights. The GFS model is a coupled model, composed of four separate models (an atmosphere model, an ocean model, a land/soil model, and a sea ice model), which work together to provide an accurate picture of weather conditions. The entire globe is covered by the GFS at a base horizontal resolution of 0.5 degree. These analyses are available every 6 hours from 2004 till now.

\subsection{Methodology}

The goal of this study is to identify and introduce the most suitable wind field for simulation of storm surges in the Persian Gulf. The storm surge in combination with tide could have disastrous effect on coastal areas.

Previous researches on the wave and storm surge modeling of Persian Gulf employed either a uniform wind over the whole domain [15] or a non-uniform coarse wind field of ECMWF on the Gulf $[16,17]$. Regarding the advances in the wind observations by means of satellites, it is tried to introduce the most precise wind field for the study's purposes. 
As mentioned before, four wind sources used in this study which are QuikSCAT, ECMWF, GFS, and CCMP. Satellites usually cannot capture wind components near land-sea interface precisely. This is not seen in global numerical weather models i.e. ECMWF, and GFS which have wind data on both lands and world oceans. However, observation records are always more accurate than model prediction values. In the recent years, by increasing the number of launched satellites, some organizations like NASA combined the observations of different satellites together to overcome lags in data acquisition of each of single missions. The lags are due to some reasons such as cloud coverage of sky, long time interval between consecutive satellite passes, long distance between paths of satellites, etc. Moreover, some model predictions results are employed to cover lags in the observations. The CCMP product is generated in this way, but is not yet evaluated for the Persian Gulf region. If the likely preference of a wind data set is proved for Persian Gulf, future studies could be implemented using the selected wind field.

In this study, an appropriate numerical model which is capable of modeling tide and storm surge was selected. In order to simulate the mentioned phenomenon, boundary conditions of the model and water surface forcing of the domain should be introduced. For the latter one, the wind field components from different data sets need to be selected. The boundary condition in the narrowest region of the domain, i.e. Strait of Hormoz, was given as time series of water level fluctuation. Then the numerical model was setup to be verified by means of tide gauge measurements.

\section{Numerical modeling}

\subsection{FVCOM hydrodynamic model}

FVCOM is a three-dimensional, unstructured-grid, finite-volume ocean model which solves momentum, continuity, temperature salinity, and density equations. This model is closed physically and mathematically using the Mellor and Yamada level 2.5 turbulent closure scheme for vertical mixing and the Smagorinsky turbulent closure scheme for horizontal mixing [18]. In addition, the irregular bottom topography is represented using $\sigma$-coordinate transformation. The initial development of FVCOM was started by a team effort at the University of Georgia. This model solves primitive equations in both Cartesian and Spherical coordinates. The momentum equations for Cartesian coordinate are shown in equations 1 and 2. 


$$
\begin{aligned}
& \frac{\partial u}{\partial t}+u \frac{\partial u}{\partial x}+v \frac{\partial u}{\partial y}+w \frac{\partial u}{\partial z}-f v=-\frac{1}{r_{0}} \frac{\partial P}{\partial x}+\frac{\partial}{\partial z}\left(K_{m} \frac{\partial u}{\partial z}\right)+F_{u} \\
& \frac{\partial v}{\partial t}+u \frac{\partial v}{\partial x}+v \frac{\partial v}{\partial y}+w \frac{\partial v}{\partial z}-f u=-\frac{1}{r_{0}} \frac{\partial P}{\partial y}+\frac{\partial}{\partial z}\left(K_{m} \frac{\partial v}{\partial z}\right)+F_{v}
\end{aligned}
$$

Where $\mathrm{x}, \mathrm{y}$, and $\mathrm{z}$ are the east, north and vertical axes in the Cartesian coordinate system; $\mathrm{u}$, $\mathrm{v}$, and $\mathrm{w}$ are velocity components; $\mathrm{r}$ is the density; $\mathrm{P}$ is the pressure; $\mathrm{f}$ is the coriolis parameter; $\mathrm{Km}$ is the vertical eddy viscosity coefficient and Fu and Fv represent the horizontal momentum terms. The current version, 2.7.1, consists of five modules of physical part (to solve advection and diffusion equations), biological, sediment, particle tracking, and ice formation module.

\subsection{Model setup}

In this study, FVCOM numerical model was used in three-dimensional Spherical mode. The simulation time step was selected as 12.5 seconds and whole simulation period was from 1 December 2008 till 31 January 2009 to include at least two neap and spring tides. The Coriolis Effect was considered in the model runs. Open boundary condition at Hormoz Strait was obtained from TPXO 7.1 ocean tide model. In the recent years, scientists use different assimilated ocean tide models such as NAO, FES, TPXO, and etc. to introduce tidal fluctuations to their hydrodynamic simulations. These models solve the hydrodynamic equations all over the oceans and then combine the results with both altimetry satellite water level observations and tide gauge records using data assimilation methods. TPXO 7.1 is one of the most recent versions of global tide solution developed by Egbert et al. [19, 20] using the inverse scheme OTIS (Oregon State University Tidal Inversion Software) to assimilate observation data to the hydrodynamic equations by the representer approach. The tide is provided as amplitudes of earth relative sea surface elevation for eight primary (M2, S2, N2, $\mathrm{K} 2, \mathrm{~K} 1, \mathrm{O} 1, \mathrm{P} 1$, and Q1 and two long-period (Mf and Mm) harmonic constituents on a 0.25 deg by 0.25 deg full global grid. In the previous hydrodynamic models of Persian Gulf [21], predicted tidal elevation of one point at Hormoz Strait has been employed as the open boundary condition. In that method, surface elevation is assumed to be constant along the strait and amplitude and phase differences between north and south of the strait were ignored, which is not realistic. In this study, the mentioned method is replaced by applying different tide amplitudes and phases along the strait which are obtained from TPXO7.1 package of harmonic constituents. 
In order to evaluate the performance of using both boundary condition types, a sensitivity analysis was conducted over a period of two weeks which includes both neap and spring tides. One of these simulations was forced by wind over the Gulf and a constant tidal constituents along Hormoz Strait open boundary which were provided by NCCI. The other simulation has employed the same wind forcing and TPXO tidal constituents which vary along the open boundary. The former boundary condition consists of four main tidal constituents (M2, S2, K1, and O1) and the latter one consists of ten tidal constituents (M2, S2, N2, K2, K1, O1, P1, Q1, Mf, and Mm). The water level results showed that the TPXO forced model performs better compared with NCCI forced model. The correlation coefficient of the latter one in Kangan station was 0.81 which is less than the parameter for the former one, 0.91. Moreover in Bushehr station, the NCCI forced model had a correlation coefficient of 0.84 compared with that of TPXO forced model (0.90). The better performance of TPXO forced model could be also concluded from the water level bias parameter at Buhshehr staiton, $0.27 \mathrm{~m}$ for TPXO forced model compared with $0.32 \mathrm{~m}$ for NCCI forced model. Furthermore, for the mesh generation of the study domain, the two-dimensional quality mesh generator of EasyMesh ver. 1.4 was used [22]. The main features of EasyMesh are generation of two dimensional, unstructured, Delaunay and constrained Delaunay triangulations and performing Laplacian smoothing. The unstructured grid for Persian Gulf consists of 16806 elements and 9379 nodes (Fig. 2). This grid represents finer elements near the coastline and around islands which are approximately about 500 meters.

\section{Results and discussion}

After conducting sensitivity analysis of the physical and computational parameters of the model, it was found that the hydrodynamic condition of the region depends highly on bed roughness height. Therefore, the model was calibrated by tuning the mentioned parameter and the value of 0.001 meter was selected. By simulation of water level fluctuation in the whole domain during two months, the results were extracted in three locations in which tide observation data were available. These stations were Bushehr, Imam Hasan, and Kangan. The time series of water levels under different wind fields are presented in Fig. 3 to Fig. 5.

In order to have a quantitative comparison, the following error measures were calculated: root mean square error, bias, correlation coefficient, and model skill, as described below:

$$
R M S E=\sqrt{\frac{1}{N} \sum\left(X_{p}-X_{m}\right)^{2}}
$$




$$
\begin{aligned}
& \text { BIAS }=\sum \frac{1}{N}\left(X_{p}-X_{m}\right) \\
& R=\frac{\sum\left(X_{p}-\bar{X}_{p}\right)\left(X_{m}-\bar{X}_{m}\right)}{\sqrt{\sum\left(X_{p}-\bar{X}_{p}\right)^{2} \sum\left(X_{m}-\bar{X}_{m}\right)^{2}}} \\
& \text { ModelSkill }=I_{a}=1-\frac{\sum\left(X_{p}-X_{m}\right)^{2}}{\sum\left(\left|X_{p}-\bar{X}_{m}\right|+\left|X_{m}-\bar{X}_{m}\right|\right)}
\end{aligned}
$$

In which, $N$ represents number of the data points, $X_{p}$ and $X_{m}$ are predicted and observed water levels and $\overline{X_{m}}$ and $\overline{X_{p}}$ are the mean value of observations and model results, respectively. The modelled time series of water level show more or less the same trend following the measured one. The modelling results showed that the skill factors of Kangan water level using CCMP, ECMWF, GFS, and QuikSCAT forcings are 0.917, 0.914, 0.918, and 0.915 respectively. Furthermore the correlation coefficients of Kangan water levels for the mentioned wind forcings are 0.925, 0.921, 0.926, and 0.921, respectively. It is worth mentioning that the statistical parameters are calculated for overall water level which is the sum of tide and storm surge. Due to geographical location of Persian Gulf and the wind regime of this region, the amplitude of tide is much higher than storm surge fluctuations and this will result to unrealistic statistical parameters. In order to overcome this problem, a harmonic analysis of predicted water levels was applied to the model results and the residual water levels, due to storm surge, were separated. Then statistical parameters were calculated for the time series of storm surge fluctuations. The table below shows the mentioned error measures.

According to the above table, the accuracy metrics in the Kangan station show that the skill of the model forced by GFS wind field is higher than others, which have greater difference compared with conditions that both tide and storm surge water levels were analysed statistically. This is the same in Bushehr and Imam-Hasan stations. In the latter station, the model skill of GFS, CCMP, ECMWF, and QuikSCAT forced model is 0.951, 0.947, 0.929, and 0.904. Besides the best root mean square error is obtained for GFS forced model with the value of $0.096 \mathrm{~m}$ and the worst one goes to QuikSCAT forced model with $0.124 \mathrm{~m}$. Furthermore, the Q-Q plots of the modeled water results under different wind conditions are shown in Fig. 6 to Fig. 9. These plots are depicted for Bushehr tide gauge location. In these plots, the perfect line is shown by dashed line and the best fitted line is shown by the solid one. 
It could be seen that the model underestimates positive storm surges and overestimates negative storm surges. The difference between models' output and observations is lower for GFS wind forcings compared with other wind data sources. This could be concluded from the slope of the regression line which is closer to one for GFS compared with CCMP, QuikSCAT and ECMWF. This slope that is the ratio of standard deviation of GFS forced model and observations is 0.63. This parameter is $0.60,0.53$ and 0.39 for CCMP, ECMWF and QuikSCAT forced model, respectively. Therefore, it could be concluded that GFS forced hydrodynamic model improves water level predictions in comparison with other wind models.

As the CCMP wind field is a more recent assimilated product compared to GFS wind field, the reason of slight preference of the latter one should be investigated. The surface elevation boundary condition of all hydrodynamic simulations is the same and the only difference is just surface wind conditions over Persian Gulf. So the accuracy of the wind fields will be studied in this section. The methodology is to compare wind speeds of the mentioed wind field with wind speed observations in coastal areas of Persian Gulf. There are five meteorology stations' records available in the Persian Gulf which had simultaneous data within the period of numerical modeling of this study. These stations have 3-hourly wind speed and direction data and have good spatial distribution over the Persian Gulf which is shown in figure 10 .

As it is shown, most stations are located on the northern coasts of the Persian Gulf where the tide-surge records were studied before. All of these stations are located on the coastal cities which are not far from the shoreline. As the elevations of the meteorology stations are different from each other, the following equation is applied to the raw wind speed data in order to obtain wind speeds at 10 meter height above ground. It should be mentioned that all wind fields also provide wind speed data at $10 \mathrm{~m}$ height.

$U_{10}=U_{z} \cdot\left(\frac{10}{Z}\right)^{\frac{1}{7}}$

Where $\mathrm{U}_{10}$ is 10 -m wind speed and $\mathrm{U}_{\mathrm{z}}$ is wind speed at height $\mathrm{z}$ above ground.

The wind speeds at the location of meteorology stations are extracted from each of four wind fields introduced in this study including CCMP, ECMWF, QuikSCAT, and GFS. Then they are compared with observed wind speeds at the meteorology stations. The averages of statistical parameters for all these five stations are tabulated in table 2. 
The statistical parameters for the wind speed comparison show that GFS wind field has a better similarity to the observations almost in all stations. The average of model skill of GFS wind field in these stations is $75.5 \%$ which is 3 percent more than CCMP wind field. Furthermore, the average of mean square error and correlation coefficient for all stations shows the same trend which is obvious preference of GFS wind field over the other ones. The model skill and root mean square error of each wind field for all the five stations is shown in figure 11 and 12 .

According to the above plot and table, lack of accuracy of QuikSCAT wind field is obvious in all meteorology stations. This would be due to the fact that QuikSCAT satellite has missed data in the coastal regions and at the time where cloud cover of the sky was high.

Finally, GFS wind field can be suggested as the best wind field for further hydrodynamic and wave modeling of the Persian Gulf. Because it can produce higher quality storm surge water levels in the northern coastlines of the Gulf. It should be emphasized that even a minor positive storm surge, less than 1 meter, could result in vast inundation of the flat coastal areas around the study domain, especially in the southern and north western parts of Persian Gulf.

\section{Summary and Conclusion}

The objective of this study was to evaluate the impact of wind obtained from four different sources (QuikSCAT, ECMWF, GFS, and CCMP) on the water level fluctuation of the Persian Gulf. The results of FVCOM hydrodynamic model forced by the mentioned wind products were extracted in observation points.

The model results of sea level fluctuation were compared with observed water levels obtained from tide gauges in three locations. The results show that GFS wind product could be a better forcing for simulation of storm surge in the Persian Gulf. As an example the model skill of predicted surge levels at Imam Hasan station were 0.904, 0.929, 0.847, and 0.951 for QuikSCAT, ECMWF, CCMP, and GFS, respectively. The lack of accuracy of QuikSCAT and other satellite missions could be due to sky cloudiness, orography effect, etc. ECMWF ERA-Interim which is the result of a numerical model also suffers from lack of accuracy in comparison with GFS wind field results. Cavaleri and Bertotti [23], Caires et al. [24] and Brenner et al. [25] showed the underestimation of the ECMWF wind fields. The CCMP is a new wind field product which has combined satellite measured records and background values of ECMWF wind field. In spite of the fact that CCMP is a more recent wind field than GFS, in this study it is shown that GFS could better matches with wind observations in the 
selected meteorology stations around Persian Gulf. Overally, GFS showed its capability to mitigate some of QuikSCAT's known problems and those of ECMWF and CCMP data set. These features can introduce GFS an interesting ocean wind dataset for simulation of storm surge and wave predictions in the Persian Gulf.

\section{Acknowledgements}

We thank the JPL PO.DAAC that makes the QuikSCAT and CCMP data freely available. ECMWF ERA-Interim data used in this study have been obtained from the ECMWF data server. We are also grateful to Dr. Siadat Mousavi whose valuable comments in working with numerical model made the way easier for us. 


\section{References}

[1] P. M. Ruti, S. Marullo, F. D'Ortenzio, M. Tremant, Comparison of analyzed and measured wind speeds in the perspective of oceanic simulations over the Mediterranean basin: Analyses, QuikSCAT and buoy data, J. of Marine Systems 70 (2008) 33-48.

[2] N. Agarwal, R. Sharma, S. K. Basu, A. Sarkar, V. K. Agarwal, Evaluation of relative performance of QuikSCAT and NCEP re-analysis winds through simulations by an OGCM, Deep-Sea Research I 54 (2007) 1311-1328.

[3] R. A. Weller, S. P. Anderson, Surface meteorology and air-sea fluxes in the western equatorial pacific warm pool during TOGA coupled ocean-atmosphere response experiment. J. Climate 9 (1996) 1959-1990.

[4] R. A. Weller, M. F. Baumgartner, S. A. Josey, A. S. Fisher, J. C. Kindle, Atmospheric forcing in the Arabian Sea during 1994-1995: observations and comparisons with climatology and models, Deep-Sea Res., Part II, 45 (1998) 1961-1999.

[5] N. Pinardi, I. Allen, E. Demirov, P. De Mey, G. Korres, A. Lascaratos, P. Y. Le Traon, C. Maillard, G. Manzella, C. Tziavos, The Mediterranean ocean forecasting system: first phase of implementation (1998-2001), Ann. Geophys. 21 (2003) 3-20.

[6] S. Pensieri, R. Bozzano, M. E. Schiano, Comparison between QuikSCAT and buoy wind data in the Ligurian Sea, J. of Marine Systems 81 (2010) 286-296.

[7] D. Carvalhoa, A. Rocha, M. Gómez-Gesteira, I. Alvarez, C. Silva Santos, Comparison between CCMP, QuikSCAT and buoy winds along the Iberian Peninsula coast, Remote Sensing of Environment, 137 (2013) 173-183.

[8] M. I. El-Sabh, T.S. Murty, Storm surges in the Arabian Gulf, Natural Hazards 4 (1989) 371-385.

[9] R.A. Sproson, Extreme values of total water level and total water velocity in the Arabian Gulf, Proceedings of the International Conference on Offshore Mechanics and Arctic Engineering (2008) 149-164.

[10] S. P. Pous, X. Carton, P. Lazure, Hydrology and circulation in the Strait of Hormuz and the Gulf of Oman-Results from the GOGP99 Experiment: 1.Strait of Hormuz, Journal of Geophysical Research, 109 (2004), C12037.

[11] C. Amante, B. W. Eakins, ETOPO1-1 Arc-Minute Global Relief Model: Procedures, Data Sources and Analysis, NOAA Technical Memorandum NESDIS NGDC-24 (March 2009) pp. 19. 
[12] Physical Oceanography Distributed Active Archive Center/Jet Propulsion Laboratory/NASA, The SeaWinds QuikSCAT L2B Scatterometer Ocean Winds, Version 3.0. Research Data Archive at the National Center for Atmospheric Research, Computational and Information Systems Laboratory (2000).

[13] European Centre for Medium-Range Weather Forecasts, updated monthly, ERA-Interim Project, Single Parameter 6-Hourly Surface Analysis and Surface Forecast Time Series, Research Data Archive at the National Center for Atmospheric Research, Computational and Information Systems Laboratory (2012).

[14] Physical Oceanography Distributed Active Archive Center/Jet Propulsion Laboratory/NASA, Cross-Calibrated Multi-Platform Ocean Surface Wind Velocity, 1987 - ongoing, Research Data Archive at the National Center for Atmospheric Research, Computational and Information Systems Laboratory Dataset (2010).

[15] B. Kamranzad, A. Etemad-Shahidi, M. Kazeminezhad, Wave height forecasting in Dayyer, the Persian Gulf, Ocean Engineering, 38 (2011) 248-255.

[16] M.H. Moeini, A. Etemad-Shahidi, V. Chegini, Wave modeling and extreme value analysis off the northern coast of the Persian Gulf, Applied Ocean Research, Volume 32, Issue 2 (2010) 209-218.

[17] B. Kamranzad, A. Etemad-Shahidi, V. Chegini, Assessment of wave energy variation in the Persian gulf, Ocean Engineering , 70 (2013) 72-80.

[18] C. Chen, R. C. Beardsley, G. Cowles, An unstructured grid, finite-volume coastal ocean model: FVCOM user manual, 315 pp. School for Marine Science and Technology, Univ. of Mass. Dartmouth, New Bedford,Mass (2006).

[19] G. D. Egbert, A. F. Bennett, M. G. G. Foreman, TOPEX/POSEIDON tides estimated using a global inverse model, J. Geophys. Res., 99 C12 (1994) 24821-2485.

[20] G. D. Egbert, Y. E. Svetlana, Efficient Inverse Modeling of Barotropic Ocean Tides, J. Atmos. Oceanic Technol., 19 (2002) 183-204.

[21] J. Kampf, M. Sadrinasab, The circulation of the Persian Gulf: a numerical study, Ocean Science Discussions, 2 (2005) 129-164.

[22] B. Niceno, EasyMesh Freeware, Division of Applied Physics, University of Trieste.

[23] L. Cavaleri, L. Bertotti, Accuracy of the modelled wind and wave fields in enclosed seas, Tellus, 56A (2004) 167-175.

[24] S. Caires, A. Sterl, J. R. Bidlot, N. Graham, V. Swail, Climatological assessment of reanalysis of wave data. Proc. 7th Int. Workshop on Wave Hindcasting and Forecasting, Banff, Canada (2002), pp. 21-22. 
[25] S. Brenner, I. Gertman, A. Murashkovsky, Preoperational ocean forecasting in the southeastern Mediterranean Sea: Implementation and evaluation of the models and selection of the atmospheric forcing. J. of Mar. Sys. 65 (2007) 268-287. 


\section{Figure Captions}

Figure 1. Bathymetry of Persian Gulf and the location of tide gauges

Figure 2. The computational domain for FVCOM hydrodynamic modeling

Figure 3. Comparison between the observed and predicted water levels under different wind field forcing, Kangan station

Figure 4. Comparison between the observed and predicted water levels under different wind field forcing, Bushehr station

Figure 5. Comparison between the observed and predicted water levels under different wind field forcing, Imam Hasan station

Figure 6. Q-Q plot of Bushehr storm surge observation vs. water level of QuikSCAT forced model

Figure 7. Q-Q plot of Bushehr storm surge observation vs. water level of ECMWF forced model

Figure 8. Q-Q plot of Bushehr storm surge observation vs. water level of CCMP forced model

Figure 9. Q-Q plot of Bushehr storm surge observation vs. water level of GFS forced model

Figure 10. Location of meteorology stations in the Persian Gulf

Figure 11. Model skill of different wind fields in all meteorology stations

Figure 12. Root mean square error of different wind fields in all meteorology stations

\section{Table Captions}

Table 1. Statistical parameters used for wind field assessments (during the modelling period, two months)

Table 2. Average of statistical parameters for all wind fields 


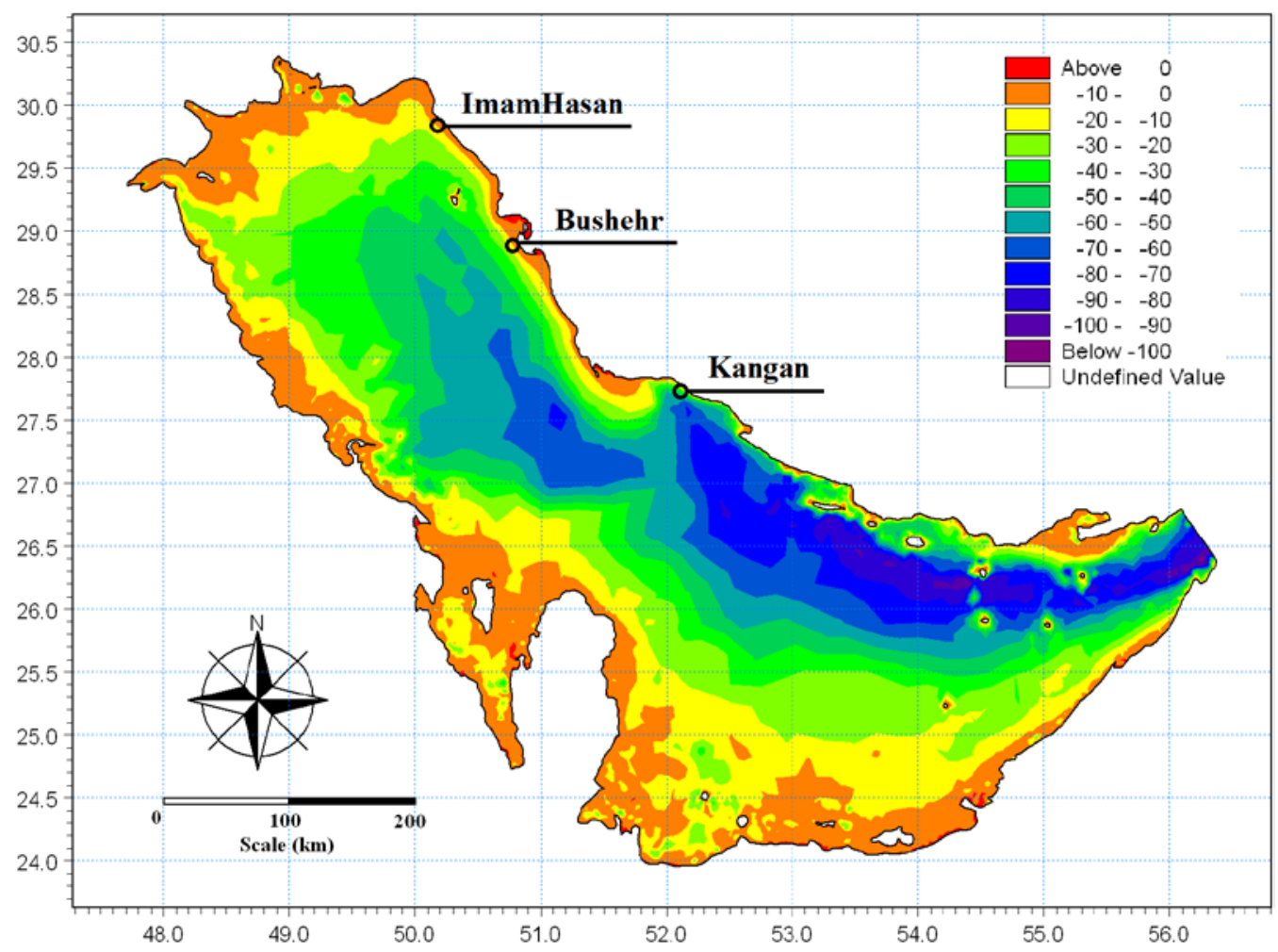

Figure 1. Bathymetry of Persian Gulf and the location of tide gauges 


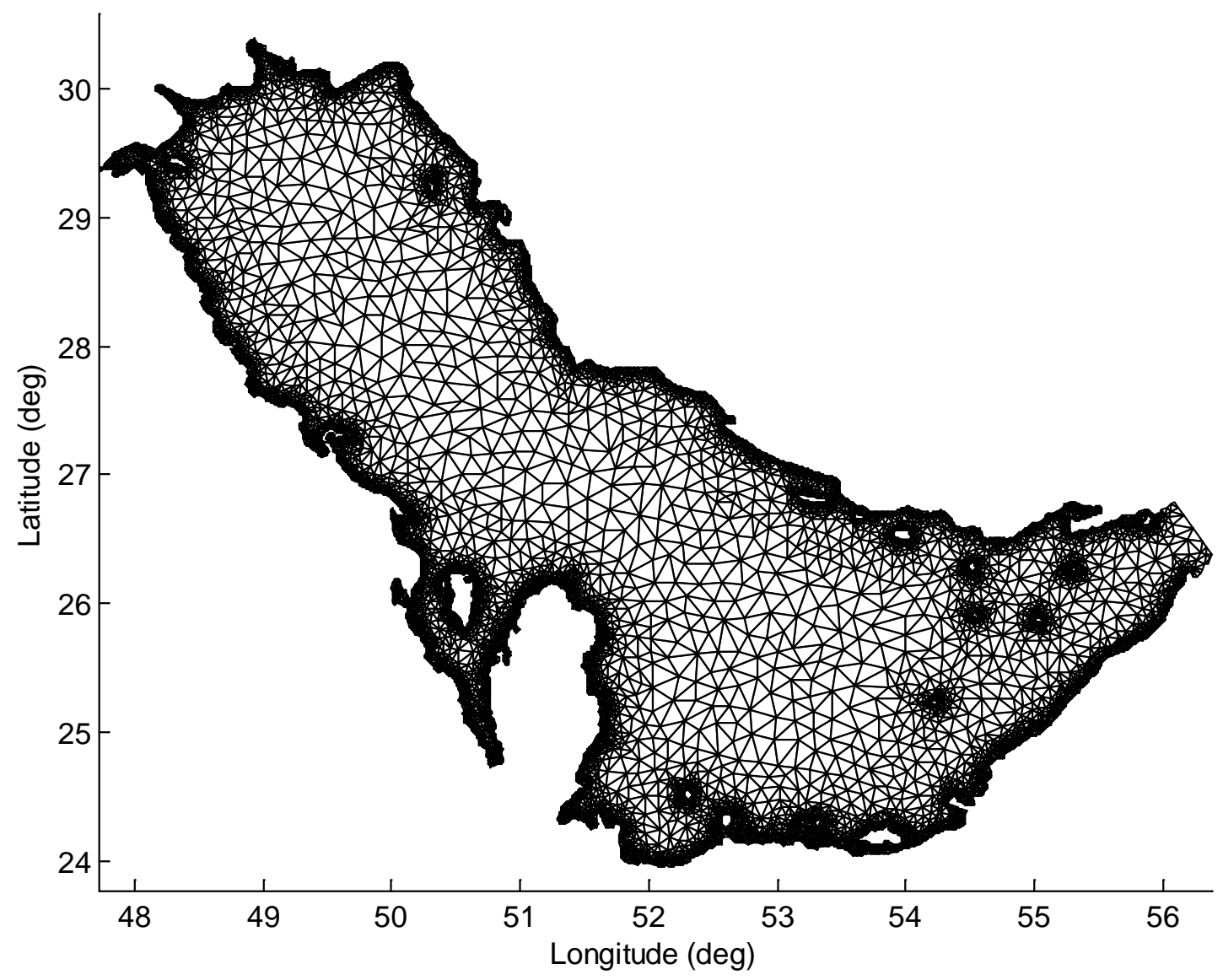

Figure 2. The computational domain for FVCOM hydrodynamic modeling 


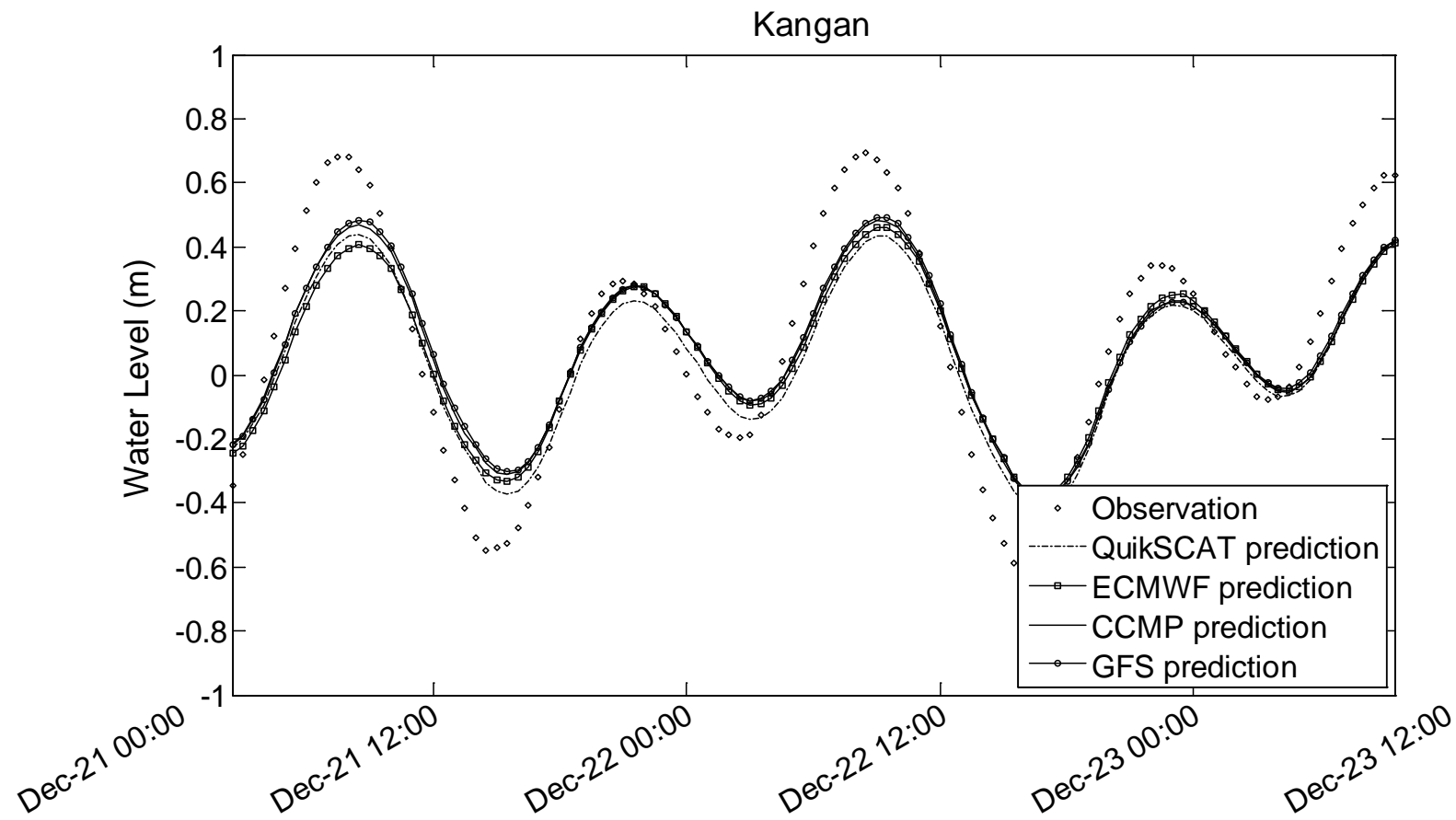

Date (Days in December 2008)

Figure 3. Comparison between the observed and predicted water levels using different wind forcing, Kangan station 


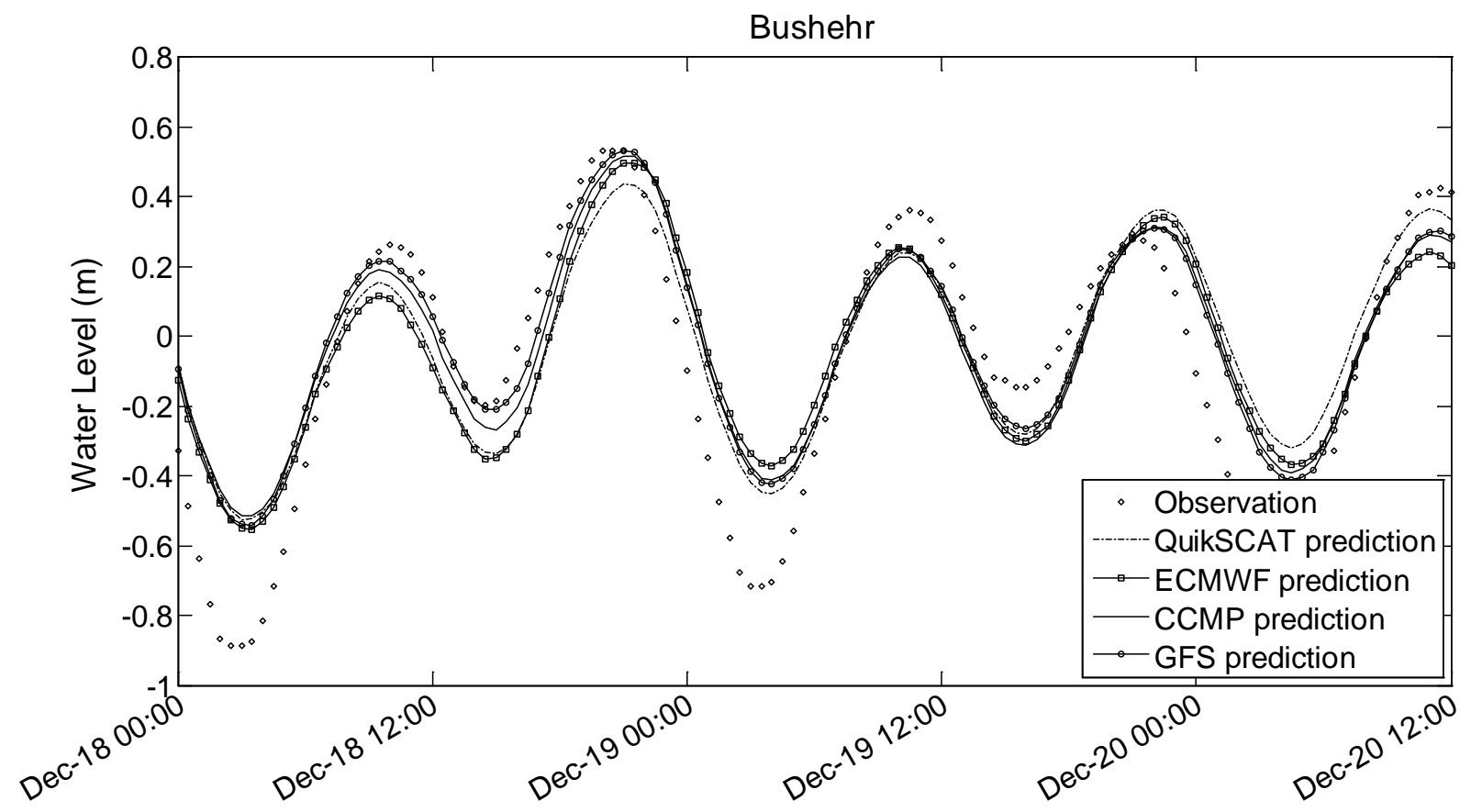

Date (Days in December 2008)

Figure 4. Comparison between the observed and predicted water levels using different wind forcing, Bushehr station 


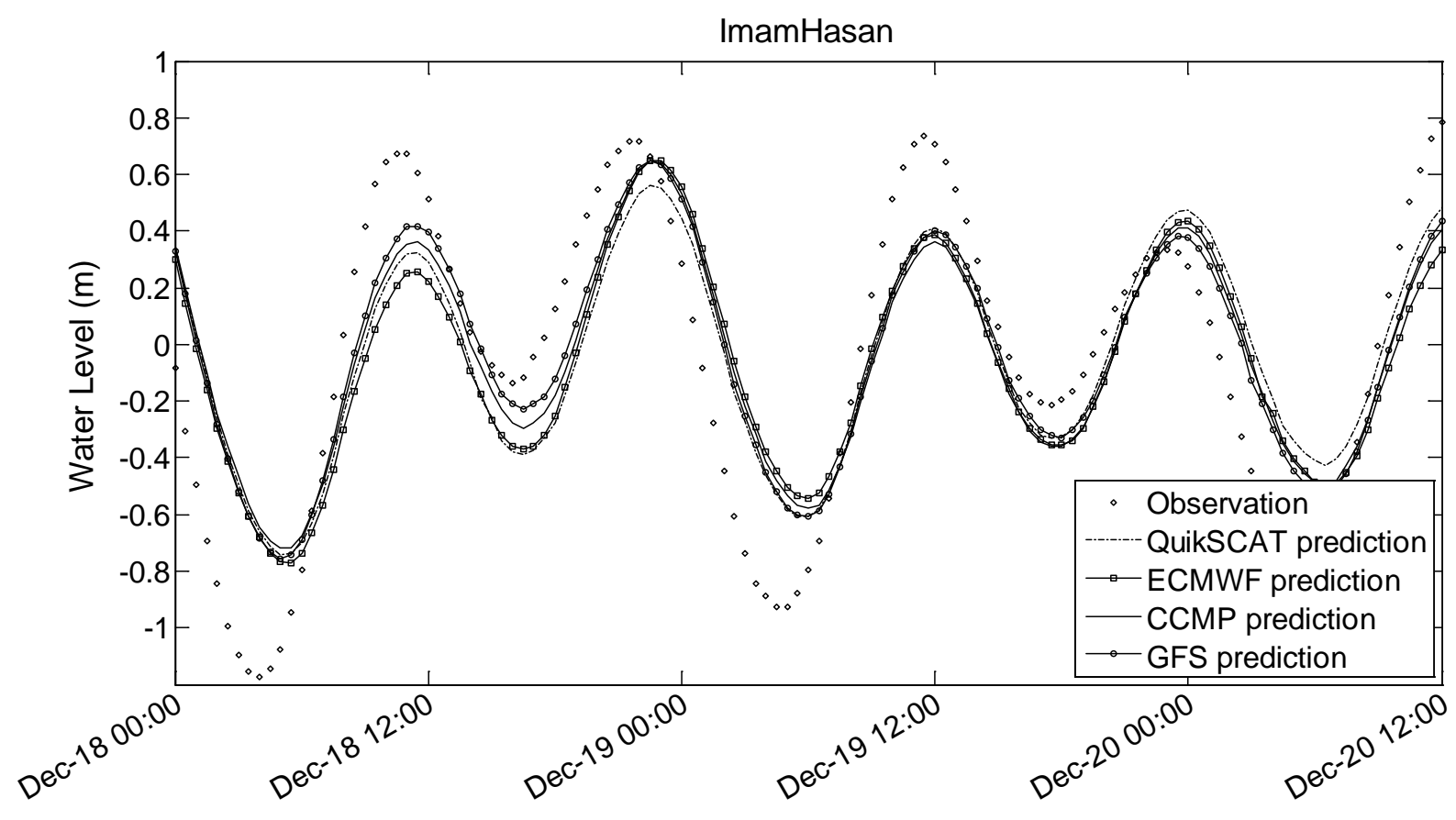

Date (Days in December 2008)

Figure 5. Comparison between the observed and predicted water levels using different wind forcing, Imam Hasan station 


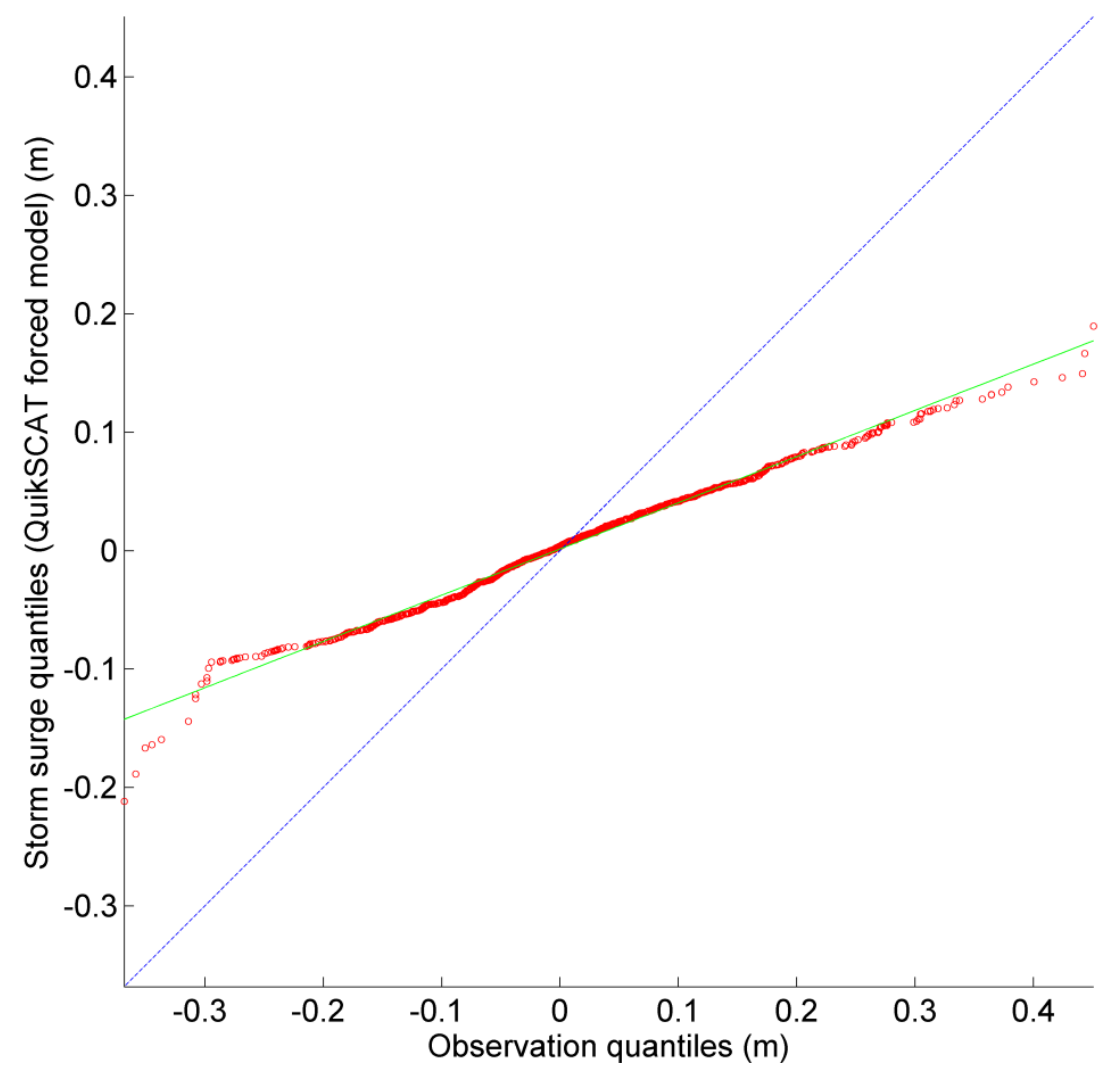

Figure 6. Q-Q plot of Bushehr storm surge observation vs. water level of QuikSCAT forced model (red dots: quantile data, green line: regression line $(\mathrm{y}=0.39 \mathrm{x})$, blue line: ideal condition $(\mathrm{y}=\mathrm{x})$ ) 


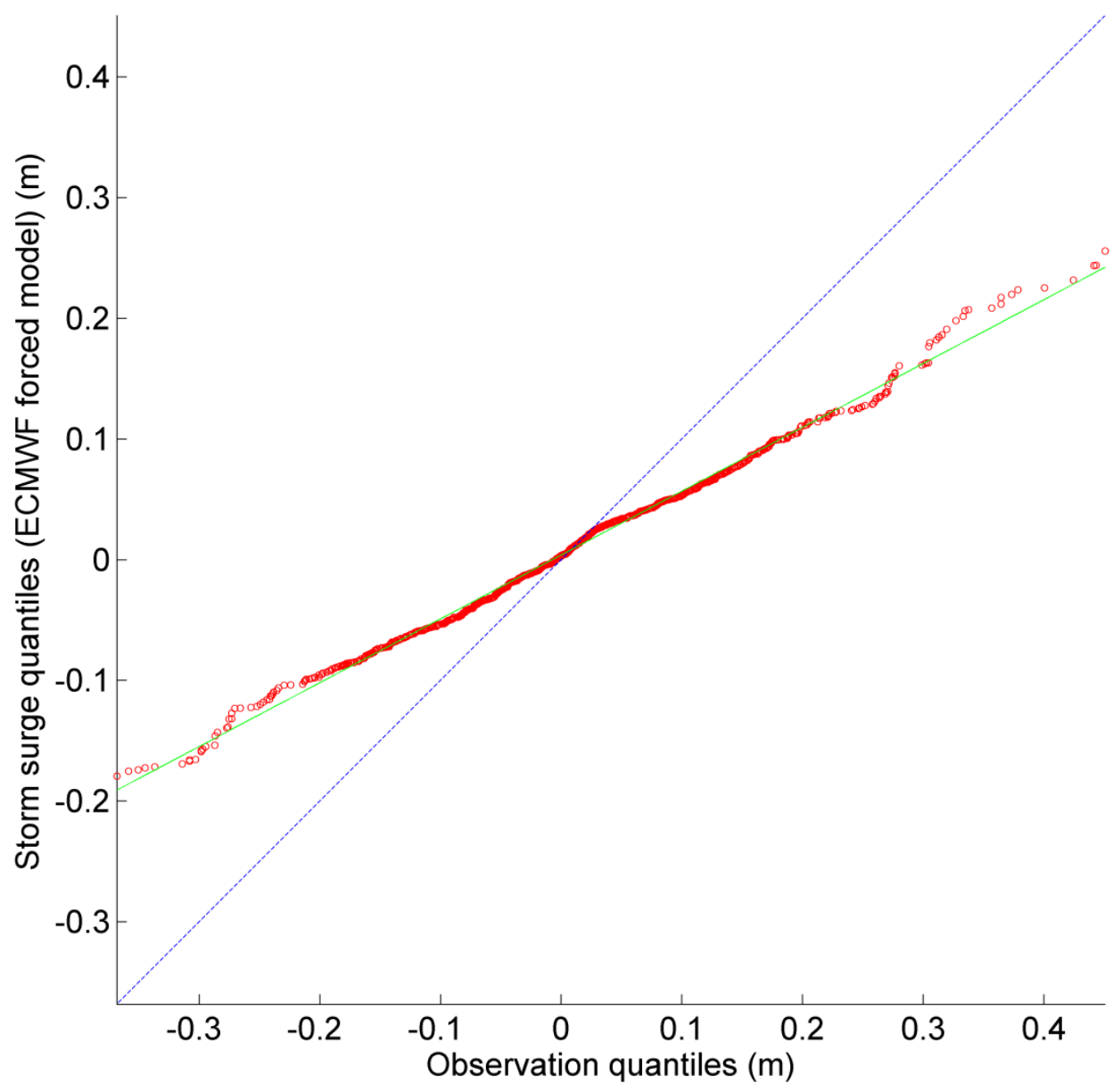

Figure 7. Q-Q plot of Bushehr storm surge observation vs. water level of ECMWF forced model (red dots: quantile data, green line: regression line $(\mathrm{y}=0.53 \mathrm{x})$, blue line: ideal condition $(\mathrm{y}=\mathrm{x})$ ) 


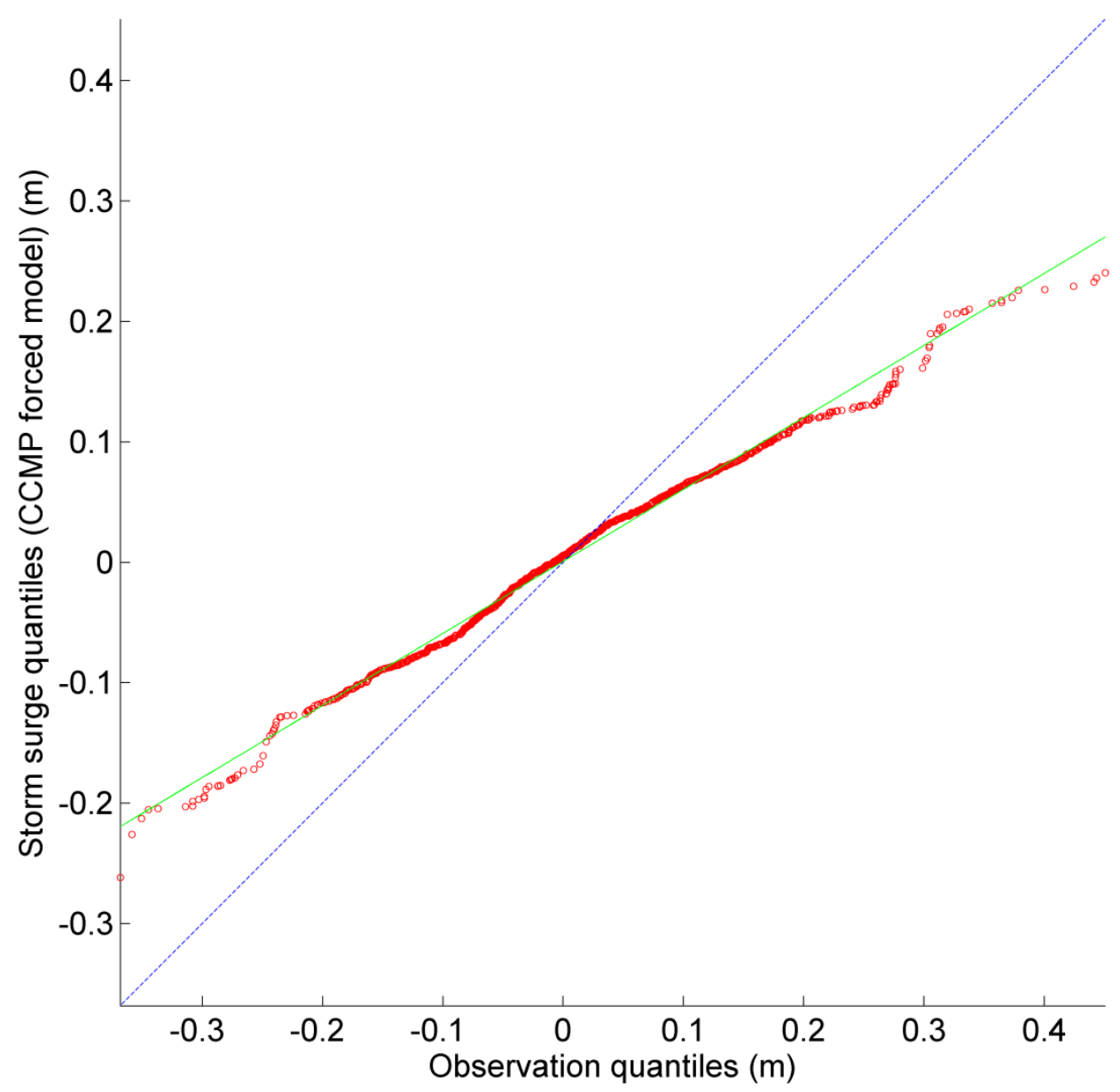

Figure 8. Q-Q plot of Bushehr storm surge observation vs. water level of CCMP forced model (red dots: quantile data, green line: regression line $(\mathrm{y}=0.60 \mathrm{x})$, blue line: ideal condition $(\mathrm{y}=\mathrm{x})$ ) 


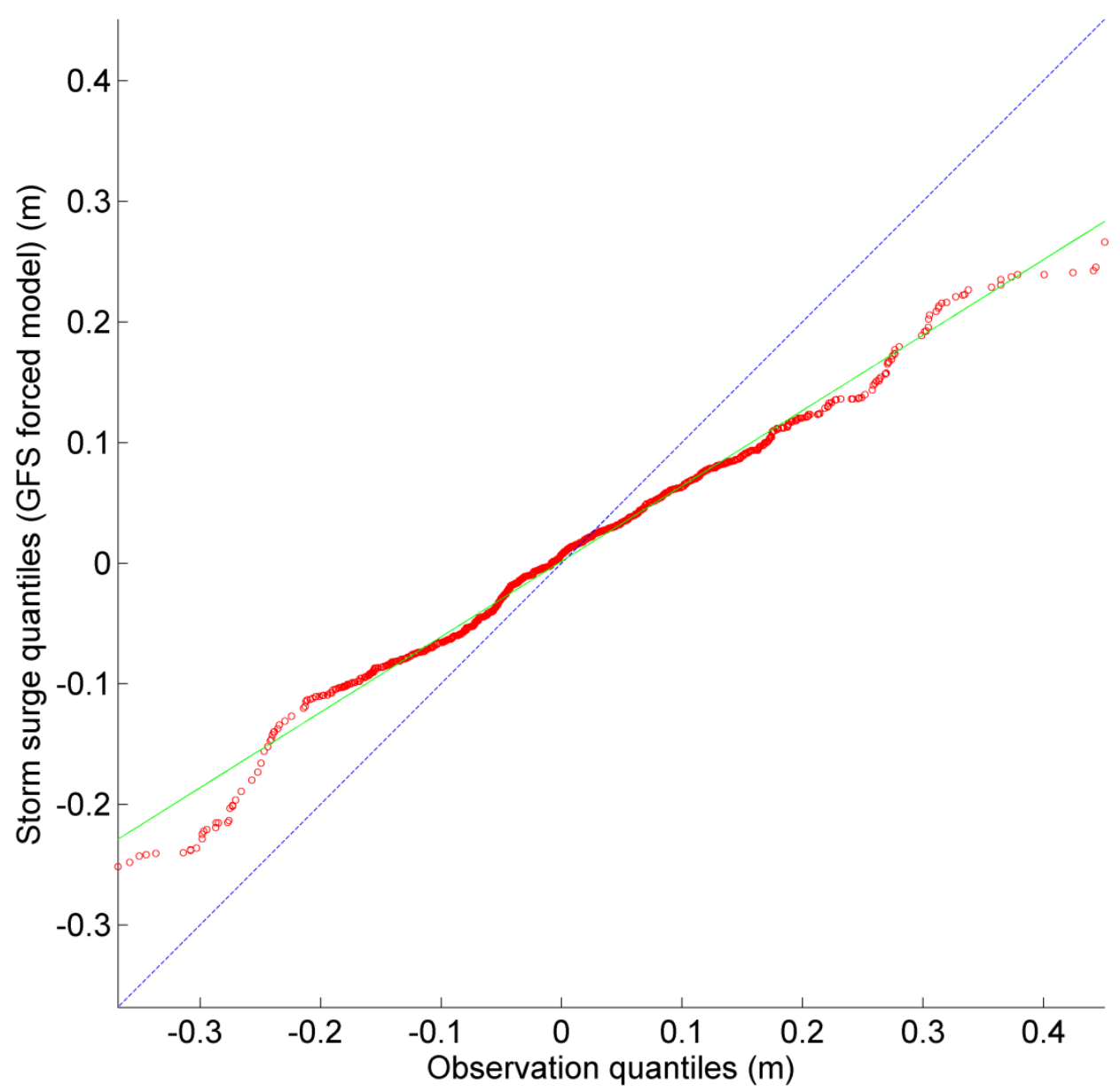

Figure 9. Q-Q plot of Bushehr storm surge observation vs. water level of GFS forced model (red dots: quantile data, green line: regression line $(\mathrm{y}=0.63 \mathrm{x})$, blue line: ideal condition $(\mathrm{y}=\mathrm{x})$ ) 


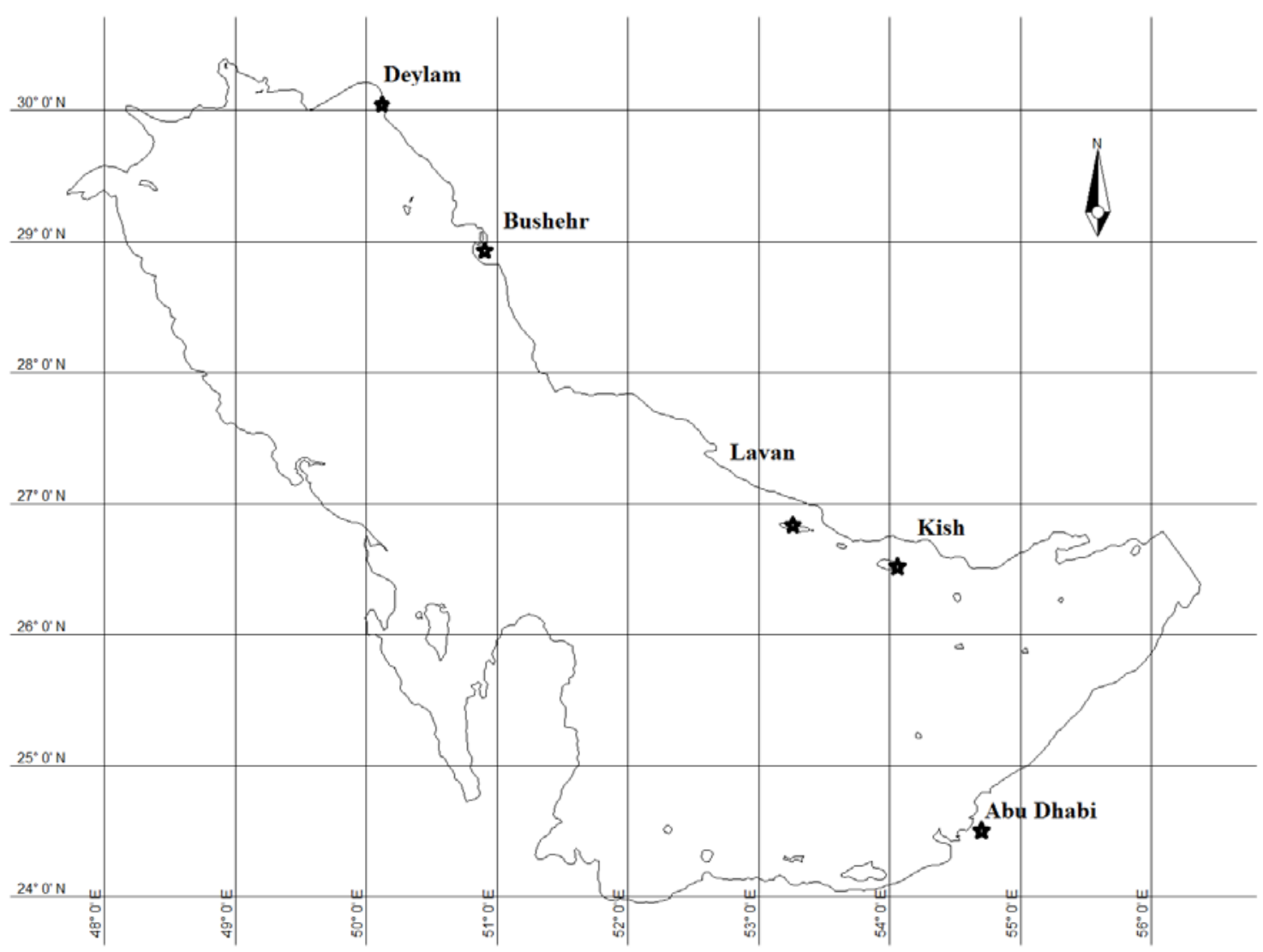

Figure 10. Location of meteorology stations in the Persian Gulf 


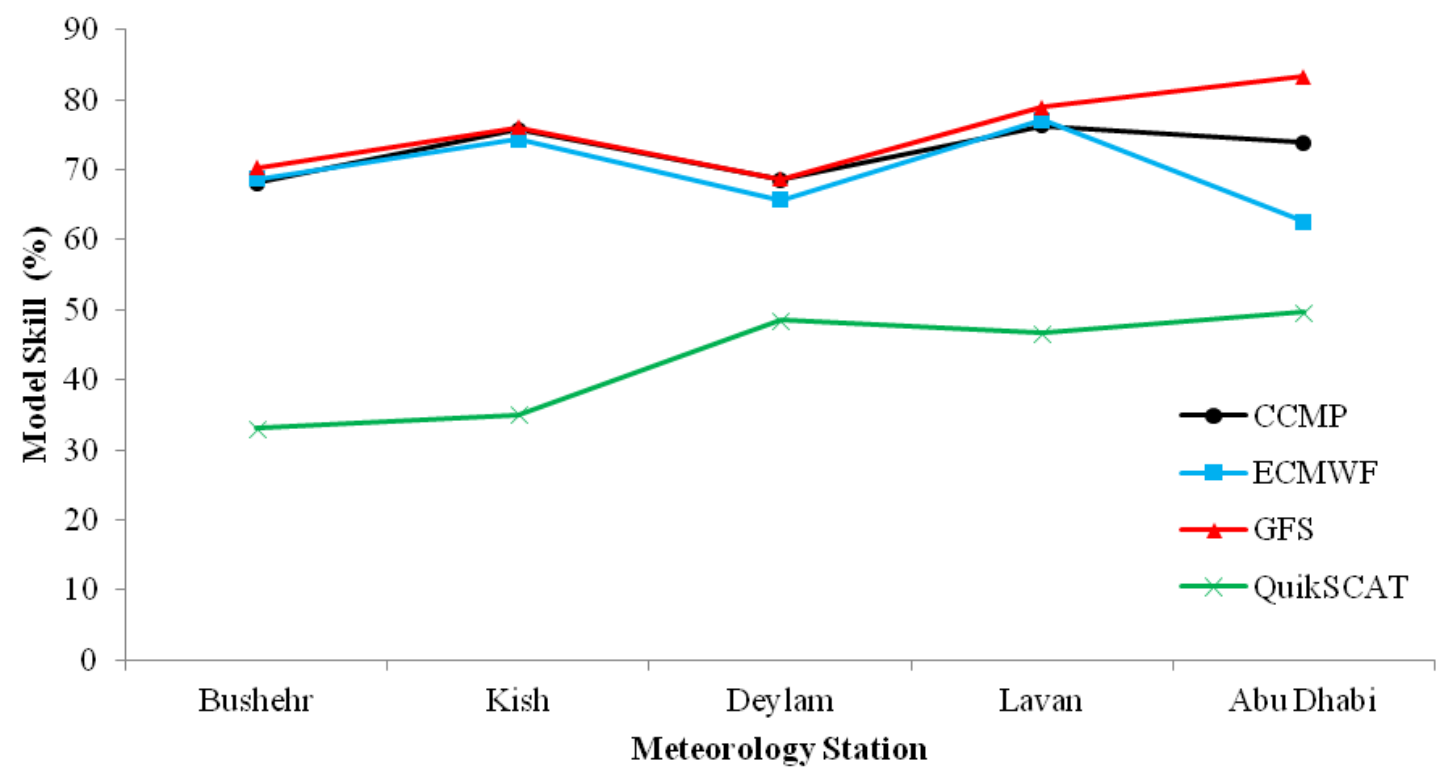

Figure 11. Model skill of different wind fields in all meteorology stations 


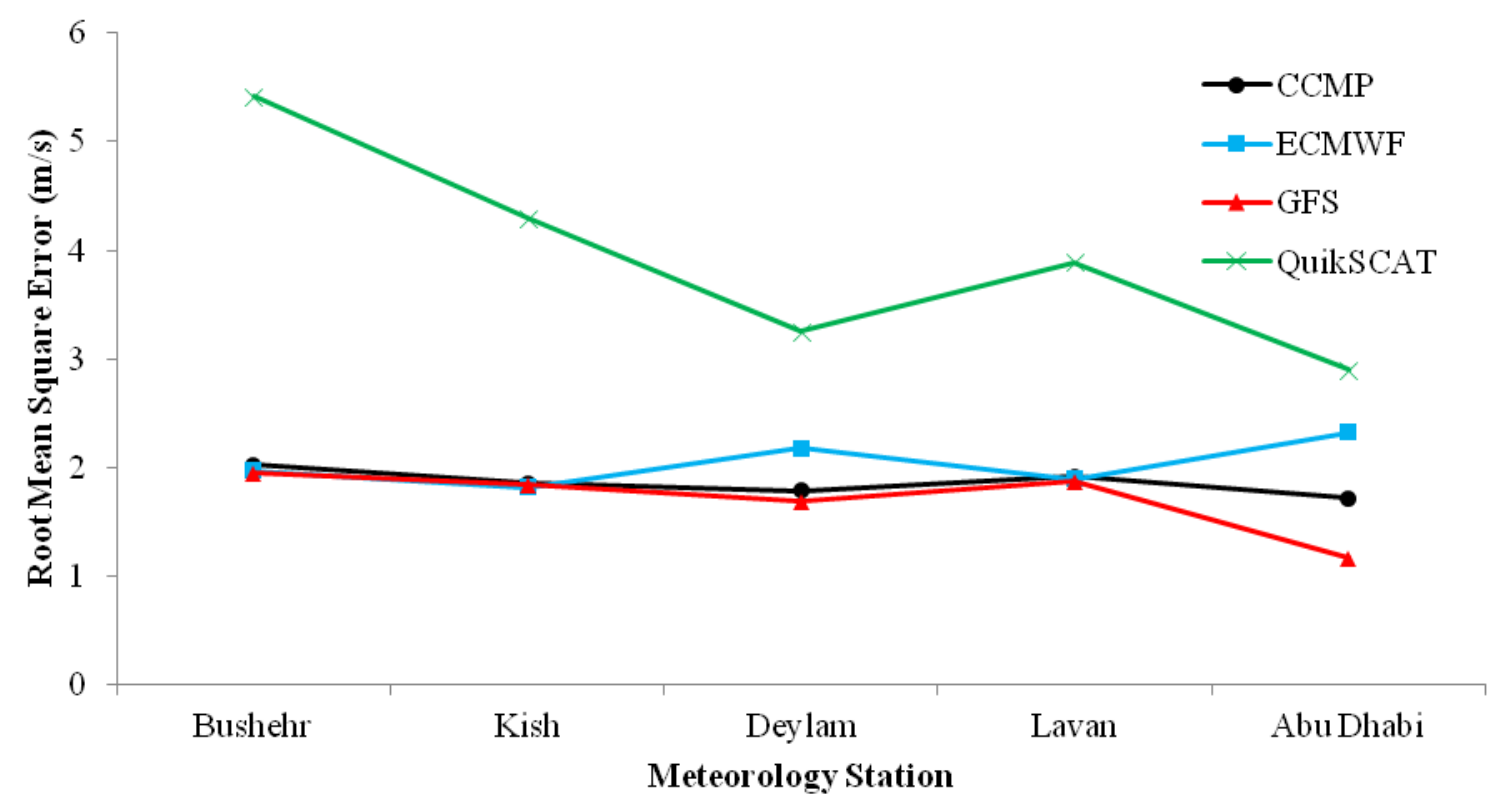

Figure 12. Root mean square error of different wind fields in all meteorology stations 
Table 1. Statistical parameters used for wind field assessments (during the modelling period, two months)

\begin{tabular}{|c|c|c|c|c|}
\hline Station & Dataset & $\begin{array}{c}R M S E \\
\text { (m) }\end{array}$ & $R$ & Skill \\
\hline \multirow{4}{*}{ Kangan } & CCMP & 0.068 & 0.787 & 0.963 \\
\hline & ECMWF & 0.074 & 0.728 & 0.954 \\
\hline & GFS & 0.066 & 0.796 & 0.966 \\
\hline & QuikSCAT & 0.082 & 0.643 & 0.941 \\
\hline \multirow{4}{*}{ Bushehr } & CCMP & 0.105 & 0.734 & 0.938 \\
\hline & ECMWF & 0.111 & 0.702 & 0.928 \\
\hline & GFS & 0.103 & 0.740 & 0.941 \\
\hline & QuikSCAT & 0.125 & 0.564 & 0.901 \\
\hline \multirow{4}{*}{$\begin{array}{l}\text { Imam- } \\
\text { Hasan }\end{array}$} & CCMP & 0.098 & 0.773 & 0.947 \\
\hline & ECMWF & 0.111 & 0.685 & 0.929 \\
\hline & GFS & 0.096 & 0.776 & 0.951 \\
\hline & QuikSCAT & 0.124 & 0.585 & 0.904 \\
\hline
\end{tabular}


Table 2. Average of statistical parameters for all wind fields

\begin{tabular}{|c|c|c|c|c|}
\hline \multirow{2}{*}{ Parameter } & \multicolumn{4}{|c|}{ Wind Field } \\
\cline { 2 - 5 } & CCMP & ECMWF & GFS & QuikSCAT \\
\hline Skill (\%) & 72.5 & 69.7 & 75.5 & 42.6 \\
RMSE (m/s) & 1.9 & 2.0 & 1.7 & 4.0 \\
R (\%) & 56.9 & 52.7 & 57.9 & 13.6 \\
\hline
\end{tabular}

